\title{
5 \\ Provisionality, play and pluralism in liminal spaces
}

\author{
MAGGI SAVIN-BADEN AND CATHY TOMBS
}

\section{Editors' introduction}

This chapter provides a stepping off point for a consideration of notions of changing identities. The chapter outlines some of the key challenges with using virtual worlds for supporting learning, and opens up a consideration of virtual identities as a new problematic for pedagogic design and adoption as part of formal and informal learning approaches. The chapter also considers the notion of opening new spaces for learning predicated upon liminality, multiple identities and central notions of play.

\section{Introduction}

To date learning in immersive worlds is under researched and the extensive possibilities for its use need to be better understood in order to realise its potential. Furthermore, the impact of learning in such worlds in terms of students' conceptions of reality, their relationship between in-world and real-world behaviour and issues of representation along with perceptions of honesty, disclosure and collaboration, bear further research. This chapter will present a study that used the methodological approach of narrative inquiry to examine students' experiences of learning in Second Life.

\section{Background}

Much of the recent research to date has been undertaken into students' experiences of virtual learning environments, discussion forums and perspectives about what and how online learning has been implemented (for example, Sharpe et al. 2005; Creanor et al. 2006; Conole et al. 2006). These 
studies, although using relatively small data sets, would seem to indicate students' experiences of e-learning are more complex and wide-ranging than many university tutors realise. Current research into learning in immersive worlds centres around cognitive learning theories. Laurillard (2002), in particular, argues for an information rich environment in which the student has control in discovering knowledge, but the discovery is supported and scaffolded by extra guidance functions. Yet virtual world learning seems to offer new perspectives relating to the study of the socio-political impact of learning in higher education. This is because virtual worlds such as Second Life (SL) are universal, not bound by time or geography, and in particular adopt different learning values from other learning spaces (Savin-Baden 2007). The overall aim of the study presented here was to explore the impact of learning in immersive worlds on end-users and their practice. The focus of this chapter, however, is on the student experience.

\section{Methodology}

Data was collected from diverse disciplines, which enabled the research themes to be explored across disciplinary boundaries. Research sites were chosen to reflect a range of uses of virtual worlds across a variety of disciplines. Data was acquired through narrative inquiry, since stories are collected as a means of understanding experience as lived and told, through both research and literature. However, narrative inquiry is seen in a variety of ways and tends to transcend a number of different approaches and traditions such as biography, autobiography, life story and more recently life course research. Narrative inquiry is used to study educational experience since it is argued by those in this sphere that humans are storytelling organisms who lead storied lives. Those who use this research method argue that stories are the closest we can come to shared experience. For example, Clandinin and Connelly argued: 'Experience ... is the stories people live. People live stories and in the telling of them reaffirm them, modify them, and create new ones' (Clandinin and Connelly 1994: 415).

Some researchers would argue that narratives are structured with a beginning, middle and an end, held together by some kind of plot and resolution. However, we would argue against this, suggesting instead that narratives do not necessarily have a plot or structured storyline, but are interruptions of reflection in a storied life. What counts as 'story' varies within methodological fields. We suggest that when using narrative inquiry it is important that the researcher is not only able to ask questions that elicit stories but also that they are able to position themselves so that stories can be analysed effectively. Further, we increasingly believe that the distinction between different types of 
narrative inquiry tends to be in the co-construction and strategies for interpretation rather than between the traditions.

\section{Data collection}

An initial review was undertaken of existing data available, via databases and ESDS Qualidata. Data was collected through semi-structured interviews face to face, by telephone and in-world with ten staff and ten students, and analysed interpretively to examine the subtext of data. The students involved were from a range of disciplines and transpired from both undergraduate and postgraduate courses.

\section{Ethics}

Ethical approval was sought from the relevant university ethics committees. Data collected was confidential. Safeguards to confidentiality included the coding of data and the code was kept separate from the raw data. All names used throughout were fictitious to preserve the identity of participants. However, it should be acknowledged that the individuals concerned might recognize some excerpts within the text used to illuminate the interpretation of data.

\section{Trustworthiness, honest and informed consent}

In the context of a study such as this, a shift was needed away from validity or trustworthiness, and the assumption that it is possible to find shared truths and clear themes and categories. Instead 'honesties' was adopted - a category that allowed for the acknowledgement that trust and truths are fragile and encourages engagement with the messiness and complexity of data interpretation in ways that reflect the lives of participants (Major and SavinBaden 2010). Honesty allowed for recognition of not only the cyclical nature of 'truths' but also that informed consent is not unproblematic. Participants signed informed consent forms and were supplied with information sheets.

\section{Findings}

Learning in immersive worlds appears to change the nature of social interaction and affects learning practices. For us it introduced questions about immersive virtual worlds and learning in such spaces that may or may not change communication, collaboration and learning practices in higher education. The findings presented here represent the themes and issues that emerged from student narratives, which include: 
- playing to learn;

- provisionality;

- dialogic learning;

- runaway pluralism.

\section{Playing to learn}

Issues were raised by students about learning, play and fun and how we also play in and through our identities in virtual spaces. Rieber et al. (1998) have suggested that the notion of 'serious play', which is characterized as an intense learning experience, involves considerable energy and commitment and suggests that serious play is important for the development of high order thinking, commitment and engagement. Playing to learn seemed to enable an exploration of the ways in which past, current and future identities are present and embodied and multiply interacting with each other in these spaces. Yet the notion of playing to learn seemed to be at odds between staff and students. Students saw play as part of or integral to learning whereas their perception was that staff did not always see it as such. Chris and Meg both saw SL as space for play and experimentation, which they felt was unexpected by staff:

I was instantly engaged. I like debating and this fitted the bill. I also don't mind a bit of humour and a few jokes and that is inevitably involved in SL ... There is a real dimension there to do all sorts of creative things you might not have thought of ... For a few the whole thing is off-putting, not really serious, you know odd boy, that sort of thing. When I speak to friends who are teachers you have to overcome their prejudice that it's all just a joke.

(Chris)

I think the course tutors, they are supportive but they can be quite directive on the course at points and I think their understanding of what education in an online space was quite different from mine. And also I was being quite experimental and in a way I think they hadn't expected and I think they were quite thrown by that.

The sense of doing things differently, playing with learning, playing around and exploring were all seen as advantages to learning in immersive virtual worlds (IVWs). Yet these advantages were often seen by staff as troublesome in the sense that the learning boundaries were not necessary controlled and managed by them, but by the students. Yet for students it was the opportunity to play, which challenged the immutability of knowledge and the perception that learning was static and tutor centred. Yet such liquidity in the learning 
also brought with it a sense of unease about the provisionality of learning and identity in such spaces.

\section{Provisionality}

Throughout the study participants spoke of a sense of everything seeming or feeling provisional and this in turn resulted in sense of liminality. Liminality is a betwixt and between state often spoke of in studies or rituals or rites of passage as a kind of in-between state. For example, Mandela (1994: 33) described his own experience of the Xhosa rite of passage into manhood, which requires payment by animals, whisky and money. In his biography, Mandela speaks of the rituals, where after the circumcision ceremony in which he was declared a man, he returned to the hut. Clearly the position in which Mandela found himself after circumcision was a liminal space; although declared a man, this was the space in which he was located before he would enter manhood properly. This theme captured the idea that the liminal quality of Second Life and the sense of chronic uncertainty challenged students to consider how to live work and learn with provisionality. For example, the location of one's avatar in spaces such as Second Life poses particular complexities, because of the interaction of five interrelated concerns that play out in the 'social space. These are:

- the 'real' body, in the sense the interlocutor of the avatar, the 'author';

- the choice of physical representation and the way the avatar is presented to others;

- the relationship between the avatar and the author;

- the author's lived experience and the social representations made through the avatar;

- the intentional meanings represented through the avatar.

Student experience seemed to indicate that language and speech were not only representations that mirrored experience, but also created it, thus the meanings ascribed and inscribed in and through avatars are always on the move. For example, Ken found that SL opened up possibilities for creativity and freedom for students:

If you let your restraints go and see the funny side of it then it becomes imaginative fun and very creative. I once answered a questionnaire Dave had and it asked how you would feel if your avatar died. I said it would be like losing a sort of artistic creation like a good painting. So I think it can help you to be creative. The format allows you to try out new problem solving skills. I also think it could be good for those who 
are shy of public debate and discussion. They can just watch and join in a disguised way.

(Ken)

For Ken the lack of restraint allowed for experimentation in new learning spaces and the opportunity to explore and play with learner identity. Further, the notion of avatar as art indicated a sense of it being both a creative expression and an extension of one's self. It might be that liminality could be seen as a trope for understanding avatar identity/pedagogy, or possibly that provisionality and representation might be seen as subcategories of liminality itself. Yet it is probably more likely that provisionality and representation are issues that inform our understanding of liminality. For example, struggles with understanding of what might constitute provisionality and how representation affects avatar identity and avatar pedagogy seemed to influence different forms and formulations of liminality that occur in IVWs. Thus issues of provisionality and representation and their relationship with liminality introduced questions about whether liminality differs in real life (RL) compared with 3D virtual worlds and whether different forms of liminality exist and /or can be delineated.

\section{Dialogic learning}

Dialogic learning is learning that occurs when insights and understanding emerge through dialogue in a learning environment. It is a form of learning where staff and students draw upon their own experience to explain the concepts and ideas with which they are presented, and then use that experience to make sense for themselves and also to explore further issues. The promotion of such forms of learning can encourage both staff and students to critique and challenge the structures and boundaries within higher education and industry, whether virtual or face to face. This is because learning through dialogue brings to the fore, for students and tutors, the value of prior experience to current learning and thus can engage them in explorations of and (re)constructions of learner identity. However, Flecha (2000) has developed the concept of dialogic learning further, suggesting seven principles that include egalitarian dialogue, the valuing of cultural intelligence and transformation.

In this study SL was seen as a more informal learning space by students than discussion forum, and therefore students felt more able to ask questions about assignments and tutor expectations of both the standard of work expected and their participation in seminars. However, it also allowed opportunities for students to question what counted as learning and what learning meant for them. For example, Kay's learning and dialogue was something that was continually changing and on the move:

I find that throughout this course and other things that I do that people talk about learning in lots of different ways. So it means the same thing 
every time they're using it and actually when you try and pin it down it disappears, what we're talking about. We're not quite talking about the same thing. And the learning for me that's coming from Second Life, it doesn't quite answer your question I don't think, but it's giving me almost, not quite a mirror but something, a trigger to look at other things, why am I reacting in this way, to what I'm seeing? Some of the things I've been saying to you. And it's forcing me to look anew at things, looking in a different way at things and I think that's quite powerful.

(Kay)

Such a sense of liminality prompted her to question her own pedagogical stance and explore issues of agency and identity in both RL and SL. Yet thinking of the impact of learning in such spaces and the shift in dialogue occurring also raised issues for students in terms of the imposition of pedagogic frameworks and models by staff on students. For example Meg argued:

I don't know whether it will or whether it won't [virtual worlds will enhance learning in the future] - I think it's here to stay but I think the problem is that it can go the same way as virtual learning environments and be very contained and linear and I know there are projects that are already doing that - they're moving Gilly Salmon's five steps to good e-learning or whatever she calls it, um into Second Life and I'm not sure that's what it's about, so I'm kind of quite unhappy with some of that - I do think it's quite experimental and I do think that people are being prepared to take risks and I think it's starting to interrupt knowledge and what learning means a bit more in higher education and I'm glad about that because I don't think there's enough of that going on. We're too obedient ...

(Meg)

For Meg the imposition of frameworks from virtual learning environments seemed to restrict dialogic possibilities and impose containment that was seen as unhelpful and unnecessary. For her the linguistic and dialogic shifts were coupled with a sense of pluralism and chaotic-ness, and a sense of things being out of control was something she valued in a way that others perhaps did not.

\section{Pluralism}

Pluralism stresses the difference between potential and actual power and in this instance refers to the potential or the possibility of power, rather than actual power of such a position. Further, although one of the authors have argued elsewhere for the importance of liquid learning (Savin-Baden 2007) pluralism is both a space of possibility and also of unruliness. There was a sense across the data that anything and everything was possible. Although 
many participants acknowledged this to be a somewhat utopian stance, the idea of the possibility of 'runaway' pedagogy, although not spoken quite in those terms, appealed to many. The kinds of pluralism seen in SL related not just to the idea of power flowing from multiple sources, but that power was often intersecting, divided and confused by shifting and changing identities, roles and understanding of learning. This is largely because in SL power and resources changed and moved and were not subject to the political whims and constraints of RL in the same kinds of ways. Further, the lack of entrapment of identities in essentialist ways has also resulted in an interruption of RL identities, thus to some extent prompting a move away from the tendency to move towards particularity, resulting in vulnerability to discrimination as both concept and practice.

However, at the same time there were unusual issues of actual power in terms of the impact of IVWs on ascribing in world behaviours, but this affected both staff and students. The way in which digital spaces are created for staff, by commercial organizations that are politicized and contained by universities, and used by students enables, but perhaps more often occludes, ways of seeing where information is located. One of the students, Chris, reflected:

I would like to see a flourishing of all sorts of educational groups using the format. I attend a number of evening classes all now threatened by government funding problems so SL could offer an alternative. I would like to see online learning expand into this dimension as the University seems to be trying to explore. I would like to see this format used in schools in dozens of different areas.

(Chris)

The sense of pluralism therefore related to identities being on the move and almost out of control in terms of space/place/agency and in terms of both colliding and interrupting. There was also a sense of confusion occurring about issues of positioning and representation. Gee's work on video gaming offers some sense not only of the multiplicity of identities involved in online learning, but also the possibilities for relationships between some of them. One of the difficulties related to game-based learning would seem to be that of identity. Gee (2004: 112-113) developed a theory of identity, based on experience of videogaming. It is a tripartite identity comprising:

1. The real identity: who we are in the physical world.

2. The virtual identity: who we are in the virtual space. Thus, Gee argues, our virtual self should be able to 'inherit' some of our real attributes.

3. The projected identity: this refers to identity that is developed through engaging with the character, through the interaction of the first two identities. 
However, Gee's conception of the virtual self here is located in gaming and the character within the games, and his notion of identity here seems to equate with 'role' rather than identity per se. Further, he has argued that identities are projected identities, but this introduces interesting psychoanalytic difficulties. Projections are usually unwanted feelings that we invariably choose not to own. We therefore believe that someone else is thinking/feeling them instead, such as anger or judgement (see for example, Jung 1977). Avatars in Second Life seem, in general, to capture wanted elements, or the chosen components of our identities that we wish to present to/in the world. Thus in immersive worlds it would seem that the identities presented are more likely to be the functional or ideal sides rather than the projected 'unwanted' sides. The realization that one is playing with one's identities prompts both questions and realizations that our identities are troublesome and uncertain.

\section{Discussion}

What all of this does seem to point to is a form of liminality between our various identities and in-between identities. Such identities would seem to be provisional, constantly changing and thus are always necessarily on the move. When students are exposed to the SL environment they necessarily add a range of SL identities to their established RL identities such as family member, ethnicity, religious affiliation, together with such temporary RL identities as student, part-time job holder and entrant to their chosen profession.

The overarching temporary RL identity of student carries with it many possibilities of entering liminal spaces after a period of 'being stuck'. In the main, students are initially worried rather than excited about being stuck; it starts off a negative experience, normally painful to wrestle with, and can be worsened by avoidance or retreat, although ultimately can be positive if dealt with successfully. Many liminal identity issues arising in SL can be related to established areas already familiar in RL. The areas of RL liminality already experienced by students may help or hinder their understandings of their new liminal experiences in SL, which in turn can add new insights back to their existing RL liminal spaces.

Students had a significant variety of SL identities ranging over the four findings, from being positively playful and/or mischievously subversive through to being confused or interrupted, and at worst disempowered and demotivated. It is the positively playful and/or mischievously subversive identities that may offer the best way that SL can help RL sufferers, as this liminality starts by being positive: students are initially excited rather than being worried about their new experience.

These varied identities seldom sat easily with one another, therefore collision and uncertainty resulted in disquietude and a sense of fragmentation. 
Such disquietude served to confirm that identity work was not only an ongoing task but also a form of musical chairs:

There are 'musical chairs', of various sizes and styles as well as of changing numbers and position, which prompt men and women to be constantly on the move and promise no 'fulfilment', no rest and no satisfaction of 'arriving', of reaching the final destination, where one can disarm, relax and stop worrying.

(Bauman 2000: 33-34)

\section{Conclusion}

What this data appears to indicate is that although liminal states may share certain characteristics, the experience of liminality differs between people, and invariably relates to identity transitions and transformations in IVWs. Thus it would seem that liminal states are not only affected by the spaces in which they occur but also the pace of change. Playing to learn, provisionality, dialogic learning and pluralism are introducing new spatial zones and practices that need to be taken account of in emerging pedagogies and in explorations of student experience in higher education of the future.

\section{References}

Bauman, Z. (2000) Liquid modernity, Cambridge: Polity Press

Clandinin, D. J. \& Connelly, F.M. (1994) Personal experience methods. In: N. K. Denzin \& Y. S. Lincoln (Eds.) Handbook of qualitative research, Thousand Oaks, CA: Sage

Conole, G., De Laat, M., Dillon, T. \& Darby, J. (2006) LXP: Student experiences of technologies final report. Retrieved 19 June, 2009, from http://jisc.ac.uk/media/documents/programmes/ elearningpedagogy/lxp_project_final_report_nov_06.pdf

Creanor, L., Trinder, K., Gowan, D. \& Howells, C. (2006) LEX: The learner experience of e-learning. Final report (report under the JISC e-pedagogy 'Understanding my learner' programme), Glasgow: Glasgow Caledonian University. Retrieved 20 August, 2009, from http://www.jisc. ac.uk/whatwedo/programmes/elearning_pedagogy/elp_learneroutcomes.aspx

Gee, J.P. (2004) What video games have to teach us about learning and literacy, Hampshire: Palgrave Macmillan

Laurillard, D. (2002) Rethinking university teaching. A conversational framework for the effective use of learning technologies, London: Routledge

Major, C. \& Savin-Baden, M. (2010) A practical guide to qualitative research synthesis. Managing the information explosion in social science research, London: Routledge

Mandela, N. (1994). The long walk to freedom. London: Abacus

Rieber, L. P., Smith, L. \& Noah, D. (1998) The value of serious play, Educational Technology, $38(6), 29-37$

Savin-Baden, M. (2007) Learning spaces: Creating opportunities for knowledge creation in academic life, Maidenhead: McGraw Hill

Sharpe, R., Benfield, G., Lessner, E. \& DeCicco, E. (2005) Final report: Scoping study for the pedagogy strand of the JISC e-Learning Programme. Retrieved 19 October, 2009, from http:// www.jisc.ac.uk/index.cfm?name=elp_learneroutcomes 